\title{
Development and Validation of a GC-MS Method for the Simultaneous Quantification of Two Piperazine Designer Drugs Sold in Combination as 'Legal $X$ '
}

\author{
Patrícia Moreira, $\mathrm{MSc}^{1^{*}}$, Diana Dias da Silva, PhD ${ }^{1}$, Sara Cunha, PhD ${ }^{2}$, Maria de Lourdes \\ Bastos, PhD $^{1}$ and Helena Carmo, PhD ${ }^{1^{*}}$
}

${ }^{1}$ UCIBIO-REQUIMTE, Laboratory of Toxicology, Department of Biological Sciences, Faculty of Pharmacy, University of Porto, Rua Jorge Viterbo Ferreira, Portugal

${ }^{2}$ LAQV-REQUIMTE, Laboratory of Bromatology/Hydrology, Department of Chemistry Sciences, Faculty of Pharmacy, University of Porto, Rua Jorge Viterbo Ferreira, Portugal

\begin{abstract}
1-Benzylpiperazine (BZP) and 1-(3-trifluoromethylphenyl) piperazine (TFMPP) are piperazine drugs of abuse often taken in combination. Considering the frequency of the co-administration of BZP and TFMPP in the clinical, analytical and forensic contexts and its toxicological impact, we aimed to implement a gas chromatography-mass spectrometry (GCMS) technique for the detection and simultaneous quantification of BZP and TFMPP in plasma, urine and cell culture medium. The sample preparation involved a protein precipitation (only for plasma), an enzymatic hydrolysis, a liquidliquid extraction (only for cell culture medium), a solid phase extraction, and a perfluoroacylation derivatization. The method was optimized and fully validated, demonstrating linearity over a concentration range of $0-10 \mu \mathrm{g} / \mathrm{mL}$ for BZP and TFMPP in the three studied matrices. Limits of detection and quantification were 0.004 and $0.016 \mu \mathrm{g} / \mathrm{mL}$ in plasma, 0.002 and $0.008 \mu \mathrm{g} / \mathrm{mL}$ in urine, and $0.156-0.312$ and $0.312-0.625 \mu \mathrm{g} / \mathrm{mL}$ in cell culture medium. Extraction efficiencies ranged from $79 \%$ to $96 \%$ in plasma, $90 \%$ to $108 \%$ in urine, and $76 \%$ to $101 \%$ in cell culture medium. The method showed high sensitivity, accuracy and precision for the simultaneous detection and quantification of BZP and TFMPP in the three studied matrices and has direct application for the control of drug abuse in humans, post-mortem analysis, and research purposes.
\end{abstract}

Keywords

Piperazines, Plasma, Urine, Cell culture medium, GC-MS

\section{Introduction}

Recently, the synthesis and abuse of new psychoactive substances (NPS), including the so-called designer drugs, have greatly increased [1]. In this context, 1-benzylpiperazine (BZP) and 1-(3-trifluoromethylphenyl)piperazine (TFMPP) are the piperazines most consumed all over the world. These drugs are easily acquired through the Internet [2] and have been abused in association with the purpose of increasing their subjective effects and to promote psychostimulation similar to that elicited by 3,4-methylenedioxy-methamphetamine (MDMA, ecstasy) [3,4]. Also, all too often BZP and TFMPP are misleadingly sold as ecstasy [5-8]. The commercialized forms usually contain larger amounts of BZP than TFMPP, and the most common combination ratio found in seized tablets is 2 BZP:1 TFMPP [9-12].

Although these drugs have been massively consumed by the young attenders of electronic music nightclubs and rave parties in Australia, China and UK [13-17], they have also been a abuse drug of choice in other European countries, with the EMCDDA drug report of 2017 stating that piperazines corre-

\footnotetext{
*Corresponding author: Patrícia Moreira, MSc, UCIBIO-REQUIMTE, Laboratory of Toxicology, Department of Biological Sciences, Faculty of Pharmacy, University of Porto, Rua Jorge Viterbo Ferreira, 228, 4050-313, Porto, Portugal; and

Helena Carmo, PhD, UCIBIO-REQUIMTE, Laboratory of Toxicology, Department of Biological Sciences, Faculty of Pharmacy, University of Porto, Rua Jorge Viterbo Ferreira, 228, 4050-313, Porto, Portugal

Accepted: October 28, 2020

Published online: October 30, 2020

Citation: Moreira P, da Silva DD, Cunha S, et al. (2020) Development and Validation of a GC-MS Method for the Simultaneous Quantification of Two Piperazine Designer Drugs Sold in Combination as 'Legal X'. Ann Toxicol 2(1):15-25
} 
Citation: Moreira P, da Silva DD, Cunha S, et al. (2020) Development and Validation of a GC-MS Method for the Simultaneous Quantification of Two Piperazine Designer Drugs Sold in Combination as 'Legal X'. Ann Toxicol 2(1):15-25

sponded to $6 \%$ of the NPS reported to the EU Early Warning System [18]. These data indicate that this occurrence cannot be overlooked, particularly because there have been reports of non-fatal and fatal intoxication attributed to BZP and TFMPP $[3,8,19,20]$.

Regarding the pharmacological, toxicological or pharmacokinetic properties of BZP and TFMPP, there is limited information available. Of note, their drug interactions are yet to be completely clarified $[21,22]$. In this sense, a method for the simultaneous quantification of BZP and TFMPP would be extremely useful to clarify these interactions and to fulfill the lack of data.

Since no analytical methods were previously validated for the concomitant analysis and/or quantification of both drugs, and by virtue of the high frequency of the co-administration of both drugs and the expected toxicological impact, it was deemed of greatest significance to develop and validate a GCMS methodology that enabled the simultaneous quantification of BZP and TFMPP and that was appropriate for clinical, forensic and research purposes.

\section{Experimental}

\section{Materials}

All chemicals and reagents were of analytical grade. BZP (99.3\% purity) was acquired from Chemos GmbH (Regenstauf, Germany) and TFMPP (98\% purity) from Alfa Aesar (Karlsruhe, Germany). 4-Hydroxy-3-methoxybenzylamine hydrochloride ( $98 \%$ purity), phenylpropanolamine, triethylamine (TEA), tert-butyl methyl ether, trifluoroacetic anhydride (TFAA), $\beta$-glucuronidase (type 2) from Helix pomatia, bovine insulin, dexamethasone, gentamicin, fungizone and Williams' Medium E with L-glutamine were purchased from Sigma-Aldrich (St. Louis, Missouri). Antibiotic solution (consisting of $10,000 \mathrm{U} / \mathrm{mL}$ penicillin and $10,000 \mu \mathrm{g} / \mathrm{mL}$ streptomycin) was purchased from Invitrogen Corporations (Paisley, UK). Methanol (MeOH; HPLC-grade) was supplied by ChemLab (Zedelgem, Belgium). Ethyl acetate and hexane (HPLCgrade) were supplied by Fisher Scientific (Loughborough, UK). Hydrochloric acid $37 \%(\mathrm{HCl})$, ammonia solution $25 \%\left(\mathrm{NH}_{4} \mathrm{OH}\right)$, sodium acetate trihydrated $\left(\mathrm{C}_{2} \mathrm{H}_{3} \mathrm{NaO}_{2} .3 \mathrm{H}_{2} \mathrm{O}\right)$, trichloroacetic acid (TCA) and formic acid were purchased from Merck (Darmstadt, Germany). Sodium hydroxide $(\mathrm{NaOH})$ was obtained from VWR (Leuven, Belgium).

\section{Blank samples}

Drug free urine and plasma (blanks) were collected from adult volunteers, healthy and without history of drug use. To obtain plasma, blood was collected into heparin tubes and centrifuged at $1,600 \mathrm{~g}$ for $10 \mathrm{~min}$ at $4{ }^{\circ} \mathrm{C}$. Blank urine and plasma samples were frozen at $-80^{\circ} \mathrm{C}$. The cell culture medium used was Williams' Medium E (no L-glutamine; no sodium bicarbonate) supplemented with $1 \%$ antibiotic solution, $5 \mu \mathrm{g} /$ $\mathrm{mL}$ bovine insulin, $50 \mu \mathrm{M}$ dexamethasone, $100 \mu \mathrm{g} / \mathrm{mL}$ gentamicin and $2.5 \mu \mathrm{g} / \mathrm{mL}$ fungizone, and stored at $4{ }^{\circ} \mathrm{C}$.

\section{Calibrator samples}

Stock solutions of standards and internal standards (IS) were prepared at $1 \mathrm{mg} / \mathrm{mL}$ in $\mathrm{MeOH}$. This solvent was also used for further intermediate solutions. A set of calibrators of the two drugs were prepared for plasma $(0.016,0.08,0.4,2$ and $10 \mu \mathrm{g} / \mathrm{mL})$, urine $(0.016,0.08,0.4,2$ and $10 \mu \mathrm{g} / \mathrm{mL})$ and cell culture medium $(0.625,1.25,2.5,5$ and $10 \mu \mathrm{g} / \mathrm{mL})$ by fortifying $500 \mu \mathrm{L}$ of blank plasma, urine or cell culture medium. Each urine and plasma specimen was added of $10 \mu \mathrm{L}$ of 100 $\mu \mathrm{g} / \mathrm{mL}$ 4-hydroxi-3-methoxybenzylamine hydrochloride (IS), while cell culture medium specimens were added of $10 \mu \mathrm{L}$ of $50 \mu \mathrm{g} / \mathrm{mL}$ phenylpropanolamine (IS) before sample preparation.

\section{Sample preparation}

A sample preparation protocol was newly developed using as reference the methods previously described for amphetamines $[23,24]$.

Protein precipitation for plasma: $\mathrm{MeOH}$ was added to plasma samples at a 1:1 ratio. Samples were vortex mixed for $30 \mathrm{sec}$, then centrifuged $\left(1,600 \mathrm{~g}, 15 \mathrm{~min}\right.$ at $\left.4{ }^{\circ} \mathrm{C}\right)$, and $500 \mu \mathrm{L}$ of the supernatant were collected for subsequent enzymatic hydrolysis.

Enzymatic hydrolysis for plasma, urine and cell culture medium: Five hundred microliters of each sample were transferred into a $5 \mathrm{~mL}$ tube containing $500 \mu \mathrm{L}$ of $0.2 \mathrm{M}$ sodium acetate buffer ( $\mathrm{pH} \mathrm{5.2)}$ and $25 \mu \mathrm{L}$ of $\beta$-glucuronidase, and incubated overnight at $37^{\circ} \mathrm{C}$.

Liquid-liquid extraction for hydrolysed cell culture medium: Three successive liquid-liquid extractions of the hydrolyzed cell culture medium samples were performed by addition of $1 \mathrm{~mL}$ of tert-butyl methyl ether preceded by alkalization of the sample ( $\mathrm{pH} 11)$ with $1 \mathrm{M} \mathrm{NaOH}$. After vigorous vortex mixing and centrifugation $(1,600 \mathrm{~g}, 5 \mathrm{~min})$, the organic phase was collected and evaporated to dryness under nitrogen flow. The residue obtained was dissolved in $3 \mathrm{~mL}$ of $0.2 \mathrm{M}$ sodium acetate buffer $(\mathrm{pH} \mathrm{5.2)}$ and subjected to the further extraction.

Solid phase extraction (SPE) for plasma, urine, and cell culture medium: The totality of the sample was applied on to a $1 \mathrm{~cm}^{3}$ (30 mg) OASIS MCX SPE column (Waters, Milford, Massachusetts), immediately followed by $2 \mathrm{~mL}$ of $0.1 \mathrm{M} \mathrm{HCl}$ and $2 \mathrm{~mL}$ of $\mathrm{MeOH}$. The eluates were discarded, and the compounds of interest eluted into a glass tube using $2 \mathrm{~mL}$ of a $5 \% \mathrm{NH}_{4} \mathrm{OH} / \mathrm{MeOH}$ solution. The solution was evaporated to dryness under nitrogen flow and the tubes further left open in a desiccator with phosphorus pentoxide $\left(\mathrm{P}_{2} \mathrm{O}_{5}\right)$ overnight to eliminate residual water.

Derivatization procedure: To the dry residue, $50 \mu \mathrm{L}$ of ethyl acetate and $50 \mu \mathrm{L}$ of TFAA were added. After incubation at $70{ }^{\circ} \mathrm{C}$ for $30 \mathrm{~min}$, the samples were cooled to room temperature and dried under nitrogen flow. The obtained residue was dissolved in $100 \mu \mathrm{L}$ of ethyl acetate and $1 \mu \mathrm{L}$ was analyzed by GC-MS.

\section{Chromatographic equipment and conditions}

An Agilent 6890N gas chromatograph equipped with an Agilent 5975 mass selective detector and an Agilent MSD Productivity ChemStation for GC and GC-MSD Systems software 
Citation: Moreira P, da Silva DD, Cunha S, et al. (2020) Development and Validation of a GC-MS Method for the Simultaneous Quantification of Two Piperazine Designer Drugs Sold in Combination as 'Legal X'. Ann Toxicol 2(1):15-25

was used in the GC-MS analysis after automatic injection of $1 \mu \mathrm{L}$ of final sample extracts. Injection was performed by a Combi-PAL autosampler (CTC Analytics, Zwingen, Switzerland) in the splitless mode with pulse pressure (40 psi) at 250 ${ }^{\circ} \mathrm{C}$. A capillary column J\&W DB-5ms (30 $\mathrm{m} \times 0.25 \mathrm{~mm} \times 0.25$ $\mu \mathrm{m})$ from Agilent was employed for the separation. The carrier gas was helium at a constant flow of $1 \mathrm{~mL} / \mathrm{min}$. The oven temperature program was optimized as follows: The initial column temperature of $120^{\circ} \mathrm{C}$ was maintained for $1 \mathrm{~min}$ and then raised to $150{ }^{\circ} \mathrm{C}$ at $10^{\circ} \mathrm{C} / \mathrm{min}$ and hold at $150{ }^{\circ} \mathrm{C}$ for 5 $\mathrm{min}$, followed by a temperature ramp of $7.5^{\circ} \mathrm{C} / \mathrm{min}$ to 300 ${ }^{\circ} \mathrm{C}$, with a $2 \mathrm{~min}$ hold. Total separation run time was $31 \mathrm{~min}$. The transfer line temperature was $280{ }^{\circ} \mathrm{C}$ and the electron energy was $70 \mathrm{eV}$. A solvent delay time of $3 \mathrm{~min}$ was added to avoid solvent overloading. The Full Scan mode was used for identification of the compounds and characterization of the mass spectra, and the Selected Ion Monitoring (SIM) mode was used for quantification of the compounds (scan range 50$600 \mathrm{~m} / \mathrm{z})$.

The selected ions used for the quantitative measurements were $\mathrm{m} / \mathrm{z} 140, \mathrm{~m} / \mathrm{z} 117, \mathrm{~m} / \mathrm{z} 203$ and $\mathrm{m} / \mathrm{z} 230$ for phenylpropanolamine; $\mathrm{m} / \mathrm{z} 345, \mathrm{~m} / \mathrm{z} 69, \mathrm{~m} / \mathrm{z} 216, \mathrm{~m} / \mathrm{z} 232$ and $\mathrm{m} / \mathrm{z} 248$ for 4-hydroxy-3-methoxybenzylamine hydrochloride; $\mathrm{m} / \mathrm{z}$ 272, $\mathrm{m} / \mathrm{z}$ 91, m/z 175 and $\mathrm{m} / \mathrm{z} 181$ for 1-benzylpiperazine; $\mathrm{m} / \mathrm{z} 326, \mathrm{~m} / \mathrm{z}$ 173, m/z 200 and m/z 229for 1-(3-trifluoromethylphenyl)piperazine.

\section{Method validation}

Linearity: Working calibrators for plasma and urine $(0.016,0.08,0.4,2$ and $10 \mu \mathrm{g} / \mathrm{mL})$ and for cell culture medium $(0.625,1.25,2.5,5$ and $10 \mu \mathrm{g} / \mathrm{mL})$ were injected, along with a blank sample (IS, no analytes). The linearity of the method was evaluated by the square correlation coefficient $\left(R^{2}\right)$ of the regression curves obtained by plotting the peak-area ratio between each analyte and the IS against analyte concentration. Five calibration curves were independently obtained, and the mean slopes calculated.

Limits of detection and quantification (LOD and LOQ): The sensitivity of the method was determined by the limit of detection (LOD) and the limit of quantification (LOQ). Briefly, the $0.016 \mu \mathrm{g} / \mathrm{mL}$ (plasma and urine) and $0.625 \mu \mathrm{g} / \mathrm{mL}$ (cell culture medium) working calibrations were progressively diluted with blank plasma, urine or cell culture medium. A signal-to-noise ratio of 3 and 10 were considered adequate for estimating the LOD and LOQ, respectively. The lowest concentration found to fit these criteria was injected at least five times and the coefficient of variation (CV\%) was calculated.

Sample stability: The sample stability was evaluated at three levels of concentration in plasma and urine samples $(0.016 \mu \mathrm{g} / \mathrm{mL}, 0.4 \mu \mathrm{g} / \mathrm{mL}$ and $10 \mu \mathrm{g} / \mathrm{mL})$ and in cell culture medium samples $(0.625 \mu \mathrm{g} / \mathrm{mL}, 2.5 \mu \mathrm{g} / \mathrm{mL}$ and $10 \mu \mathrm{g} / \mathrm{mL})$. The working calibrators were prepared and extracted on the same day (day 0 ) or stored at $4{ }^{\circ} \mathrm{C}$ and $-20^{\circ} \mathrm{C}$ and extracted after 7 days (plasma, urine and culture medium) or 30 days (plasma and urine). The stability was evaluated comparing the signal of samples extracted and analysed 7 and 30 days after being stored with the signal of the same freshly processed samples (day 0). The CV\% was calculated.
Derivatized samples stability: The stability of the derivatized samples was evaluated at three levels of concentration in derivatized plasma and urine extracts $(0.016 \mu \mathrm{g} / \mathrm{mL}, 0.4$ $\mu \mathrm{g} / \mathrm{mL}$ and $10 \mu \mathrm{g} / \mathrm{mL}$ ) and in derivatized cell culture medium extracts $(0.625 \mu \mathrm{g} / \mathrm{mL}, 2.5 \mu \mathrm{g} / \mathrm{mL}$ and $10 \mu \mathrm{g} / \mathrm{mL})$. These samples were stored at $4{ }^{\circ} \mathrm{C}$ and injected for five days. The stability was evaluated comparing the signal of samples injected during five days after being derivatized, with the signal of the same freshly derivatized samples. The CV\% was calculated.

Precision: Inter-day and intra-day precision were evaluated at three levels of concentration in plasma, urine and cell culture medium samples, and expressed as the CV\%.

For all matrices, the inter-day precision was determined by the analysis, at five different days, of five independent samples $(0.016 \mu \mathrm{g} / \mathrm{mL}, 0.4 \mu \mathrm{g} / \mathrm{mL}$ and $10 \mu \mathrm{g} / \mathrm{mL}$ for plasma and urine; $0.625 \mu \mathrm{g} / \mathrm{mL}, 2.5 \mu \mathrm{g} / \mathrm{mL}$ and $10 \mu \mathrm{g} / \mathrm{mL}$ for cell culture medium).

The intra-day precision of the method was performed by extracting five times the same plasma and urine sample $(0.016 \mu \mathrm{g} / \mathrm{mL}, 0.4 \mu \mathrm{g} / \mathrm{mL}$ and $10 \mu \mathrm{g} / \mathrm{mL})$ and the same cell culture medium sample $(0.625 \mu \mathrm{g} / \mathrm{mL}, 2.5 \mu \mathrm{g} / \mathrm{mL}$ and $10 \mu \mathrm{g} / \mathrm{mL})$. The intra-day precision of the equipment was determined by analyzing five times, on the same day, one sample at three different concentrations $(0.016 \mu \mathrm{g} / \mathrm{mL}, 0.4 \mu \mathrm{g} / \mathrm{mL}$ and $10 \mu \mathrm{g} /$ $\mathrm{mL}$ for plasma and urine; $0.625 \mu \mathrm{g} / \mathrm{mL}, 2.5 \mu \mathrm{g} / \mathrm{mL}$ and $10 \mu \mathrm{g} /$ $\mathrm{mL}$ for cell culture medium).

Accuracy: The accuracy of the method was assessed five times for BZP and TFMPP at three different concentrations $0.016 \mu \mathrm{g} / \mathrm{mL}, 0.4 \mu \mathrm{g} / \mathrm{mL}$ and $10 \mu \mathrm{g} / \mathrm{mL}$ for plasma and urine, and $0.625 \mu \mathrm{g} / \mathrm{mL}, 2.5 \mu \mathrm{g} / \mathrm{mL}$ and $10 \mu \mathrm{g} / \mathrm{mL}$ for cell culture medium, by calculating the percent deviation between the calculated value and the nominal value [accuracy $(\%)=($ mean calculated concentration/nominal concentration) $\times 100]$.

Extraction efficiency: The extraction efficiency for each analyte was assessed at three different concentrations 0.016 $\mu \mathrm{g} / \mathrm{mL}, 0.4 \mu \mathrm{g} / \mathrm{mL}$ and $10 \mu \mathrm{g} / \mathrm{mL}$ for plasma and urine, and $0.625 \mu \mathrm{g} / \mathrm{mL}, 2.5 \mu \mathrm{g} / \mathrm{mL}$ and $10 \mu \mathrm{g} / \mathrm{mL}$ for cell culture medium, using five replicates for each concentration.

Samples were prepared by spiking blank plasma, urine and cell culture medium with each analyte, extracted, and the IS added to each eluate before evaporation. The control samples were prepared by extracting blanks of each matrix and the analyte and IS solutions were added to each eluate before evaporation. For each analyte at each concentration, extraction efficiency was assessed by comparison of the peak area ratios of analyte to IS from extraction samples and control samples.

The recovery of the IS was independently tested at the $2 \mu \mathrm{g} / \mathrm{mL}$ and $1 \mu \mathrm{g} / \mathrm{mL}$ concentrations for 4-hydroxi-3-methoxybenzylamine hydrochloride and phenylpropanolamine, respectively.

Evaluation of interferences and specificity: Several blank samples of each matrix were processed and injected to evaluate the presence of chromatographic interferences at the retention times of the studied compounds. The GC-MS chromatograms of spiked samples and blank samples were then compared. 

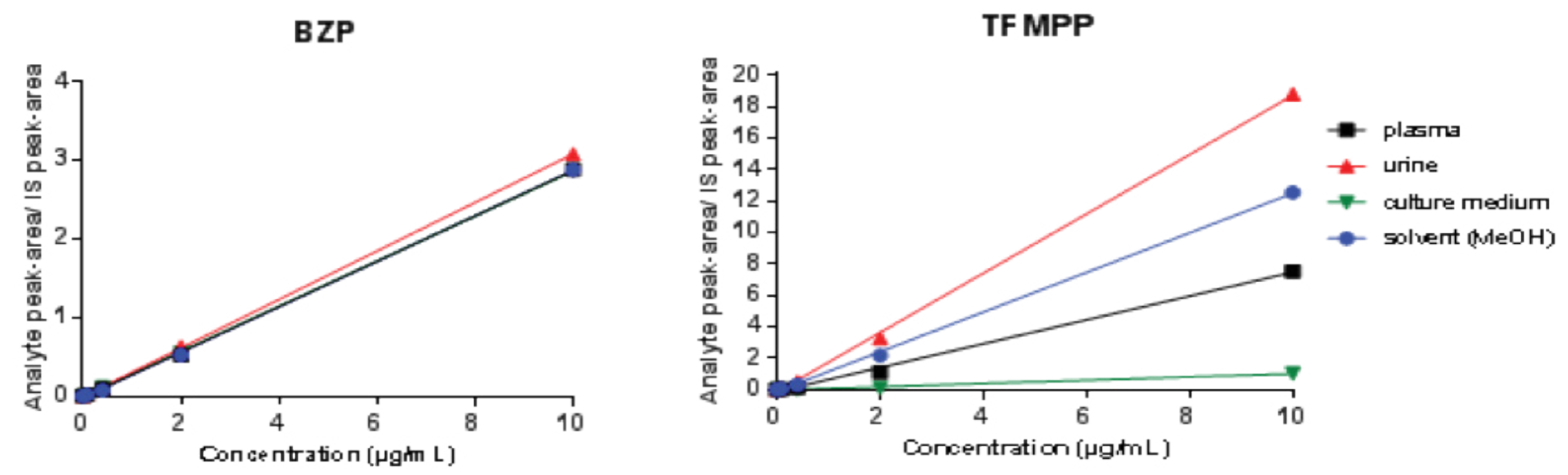

Figure 1: Calibration curves obtained for the $0-10 \mu \mathrm{g} / \mathrm{mL}$ concentration range in the matrix and solvent for BZP and TFMPP ( $\mathrm{n} \geq 5$ ).

Table 1: Monitoring conditions of the test compounds in SIM mode.

\begin{tabular}{|l|l|l|l|l|}
\hline Compound & Time interval $\mathbf{( m i n )}$ & $\begin{array}{l}\text { Retention time } \\
(\mathbf{m i n})\end{array}$ & $\begin{array}{l}\text { Quantification ion } \\
\mathbf{( m / z )}\end{array}$ & Confirmation ions (m/z) \\
\hline Phenylpropanolamine & $3-6$ & 3.5 & 140 & $117 ; 203 ; 230$ \\
\hline 4-hydroxy-3-methoxybenzylamine & $6-9.5$ & 6.85 & 345 & $69 ; 216 ; 232 ; 248$ \\
\hline BZP & $9.5-31$ & 11.2 & 272 & $91 ; 175 ; 181$ \\
\hline TFMPP & $9.5-31$ & 11.4 & 326 & $173 ; 200 ; 229$ \\
\hline
\end{tabular}

\section{Proof of applicability}

The applicability of the method could not be tested with real human samples since blood and/or urine samples from intoxicated individuals were not available for testing. To overcome this difficulty, we applied the method for the quantification of BZP and TFMPP in the extracellular exposure medium of primary rat hepatocytes after single and combined incubation with both drugs for $24 \mathrm{~h}$. After the incubation period, the extracellular media was removed for the quantification of BZP and TFMPP using the validated method. Additionally, potential metabolites that could be formed due to the metabolic activity of the primary hepatocytes, were searched for using the Full Scan mode.

\section{Results and Discussion}

\section{Sample preparation}

In order to decrease the complexity of plasma samples, the protein precipitation before SPE extraction was considered necessary. In urine samples, the hydrolysis of conjugates before SPE extraction and GC-MS analysis was necessary, since glucuronide and sulfate conjugates are not volatile, precluding the direct analysis. Furthermore, it has been previously described the elimination of BZP and TFMPP as conjugates both in humans [21,25] and animals [26-28]. The major challenge of this work was the low sensitivity of the method for TFMPP in the cell culture medium and its consequent lack of linearity. A liquid-liquid extraction before SPE extraction was optimized in order to increase the method sensitivity for TFMPP in cell culture medium and solve this challenge.

\section{Matrix effect}

The matrix effect is one of the main sources of error in analytical methods. Therefore, it is an important aspect to consider in the analysis of analytes in matrices as varied as those studied in this work, as it might impact all stages of chromatographic analysis (injection, separation, detection) and impair the quality of the results: Masking the peaks of the compounds of interest (false negatives); falsely identifying substances as impurities (false positives); increasing or decreasing the analytic signal of the detector [29-31].

Taking into consideration the diversity of matrices that we intended to validate, the matrix effect was evaluated by comparing the different calibration curves obtained in the matrix and solvent $(\mathrm{MeOH})$. As observed in Figure 1, a significant matrix effect was noted, especially for TFMPP. Therefore, the method was validated for each matrix separately. As can be depicted in Figure 1, the calibration curve obtained with the cell culture medium presented a lower slope for TFMPP, and the analytical signal appears to be decreased, which can be explained by the high lipid content of the cell culture medium. This also explains the success of the liquid-liquid extraction.

\section{Gas chromatographic separation}

The 4-hydroxy-3-methoxybenzylamine hydrochloride (IS) showed an extractive and chromatographic behavior similar to the analytes and adequate retention time in plasma and urine. However, in cell culture medium, the liquid-liquid extraction drastically decreased the sensitivity of this IS, so another compound, phenylpropanolamine, was tested as IS to be used in the cell culture medium. This compound showed an extractive and chromatographic behavior similar to the analytes and adequate retention time and for these reasons was selected as the IS to be used in this matrix.

The SIM ions were selected taking into account their 
Citation: Moreira P, da Silva DD, Cunha S, et al. (2020) Development and Validation of a GC-MS Method for the Simultaneous Quantification of Two Piperazine Designer Drugs Sold in Combination as 'Legal $X$ '. Ann Toxicol 2(1):15-25

specificity and their abundance in the mass spectra. For each substance at least four ions were chosen, one for quantification and the others for confirmation (Table 1). The selected quantification ions and the retention times for phenylpropanolamine, 4-hydroxy-3-methoxybenzylamine, BZP and TFMPP are shown in Table 1. The chromatograms in Figure 2

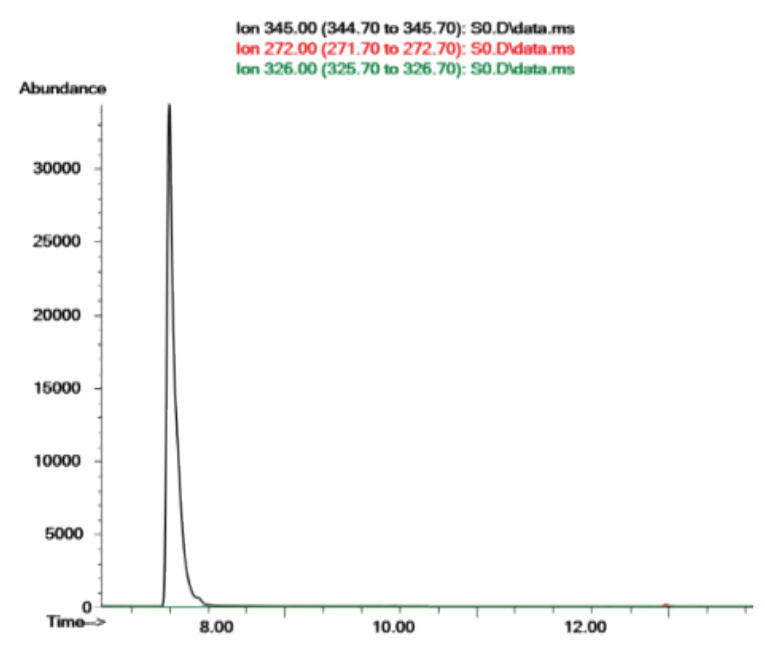

Ion 345.00 (344.70 to 345.70): S1.Dldata.ma

Ion 272.00 (271.70 to 272.70$)$ : S1.Dldata.ms
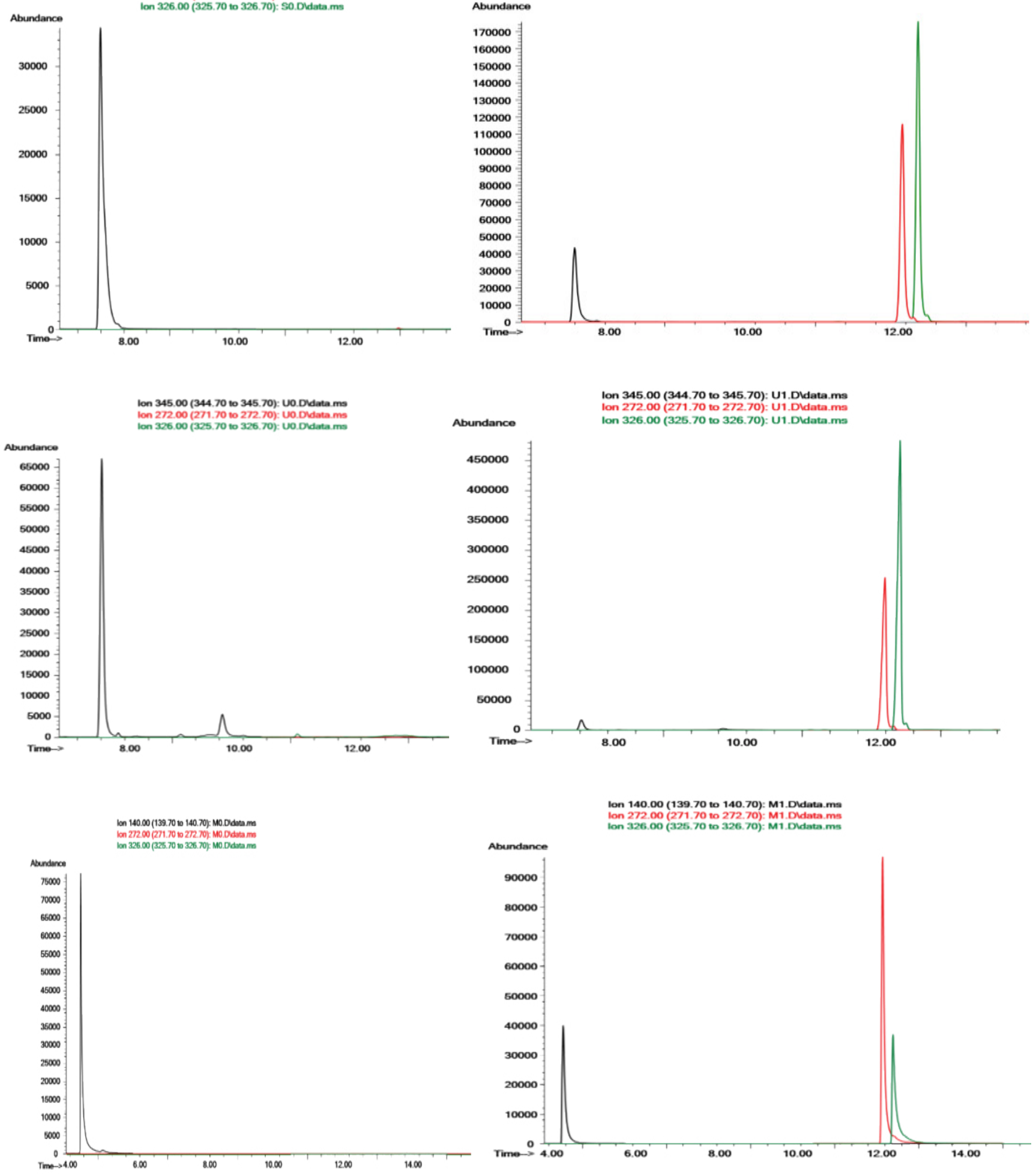

Figure 2: SIM mode chromatograms obtained after the injection of a blank (left panel) and the respective calibrator sample (right panel) spiked with a mixture of phenylpropanolamine (IS), 4-hydroxy-3-methoxybenzylamine (IS), BZP, and TFMPP at a concentration of 10 $\mu \mathrm{g} / \mathrm{mL}$, of plasma (A), urine (B) and cell culture medium (C). The chromatograms were obtained with the following ions: $\mathrm{m} / \mathrm{z} 140$ for phenylpropanolamine ( $3.5 \mathrm{~min}$ ), $\mathrm{m} / \mathrm{z} 345$ for 4-hydroxy-3-methoxybenzylamine (6.85 min), m/z 272 for BZP (11.2 min) and m/z 326 for TFMPP (11.4 min). 
Citation: Moreira P, da Silva DD, Cunha S, et al. (2020) Development and Validation of a GC-MS Method for the Simultaneous Quantification of Two Piperazine Designer Drugs Sold in Combination as 'Legal X'. Ann Toxicol 2(1):15-25

Table 2: Calibration curves for BZP and TFMPP in plasma, urine and cell culture medium.

\begin{tabular}{|l|l|l|l|}
\hline & Equation & Range $(\mu \mathrm{g} / \mathrm{mL})$ & $\mathbf{R}^{\mathbf{2}}$ \\
\hline Plasma & & & 0.9996 \\
\hline BZP & $\mathrm{y}=0.1391 \mathrm{x}-0.00635$ & $0-10$ & 0.9993 \\
\hline TFMPP & $\mathrm{y}=0.2147 \mathrm{x}-0.01388$ & $0-10$ & \\
\hline Urine & & & 1.0000 \\
\hline BZP & $\mathrm{y}=0.3233 \mathrm{x}+0.00010$ & $0-10$ & 0.9996 \\
\hline TFMPP & $\mathrm{y}=0.5118 \mathrm{x}-0.01997$ & $0-10$ & \\
\hline Cell culture medium & & & 0.9983 \\
\hline \multicolumn{1}{|c|}{ BZP } & $\mathrm{y}=0.1970 \mathrm{x}-0.03478$ & $0-10$ & 0.9986 \\
\hline TFMPP & $\mathrm{y}=0.2140 \mathrm{x}-0.03845$ & $0-10$ & \\
\hline
\end{tabular}

$(n \geq 5)$

Table 3: LOD and LOQ ( $\mu \mathrm{g} / \mathrm{mL})$ for BZP and TFMPP in plasma, urine and cell culture medium.

\begin{tabular}{|l|l|l|l|l|}
\hline \multicolumn{2}{|l|}{ LOD $(\mu \mathrm{g} / \mathrm{mL})$} & \multicolumn{2}{l|}{ LOQ $(\mu \mathrm{g} / \mathrm{mL})$} \\
\hline & BZP & TFMPP & BZP & TFMPP \\
\hline Plasma & $0.004(11 \%)$ & $0.004(12 \%)$ & $0.016(13 \%)$ & $0.016(12 \%)$ \\
\hline Urine & $0.002(12 \%)$ & $0.002(11 \%)$ & $0.008(4 \%)$ & $0.008(6 \%)$ \\
\hline Cell culture medium & $0.156(18 \%)$ & $0.312(21 \%)$ & $0.312(20 \%)$ & $0.625(15 \%)$ \\
\hline
\end{tabular}

(CV\%)

correspond to SIM mode chromatograms, where it is possible to see a good separation between the compounds and a low effect of bleeding, which proves that the column is adequate for this analysis.

\section{Method validation}

Linearity: Calibration curves were linear for all analytes in the range of $0-10 \mu \mathrm{g} / \mathrm{mL}$. This range of linearity was observed for the three matrices studied. The acceptable criteria for linearity is a calibration curve with a square correlation coefficient of 0.99 or higher [32], and in this study the square correlation coefficients were always greater than 0.99 (Table 2).

Limits of detection and quantification: The LOD for both analytes was $0.004 \mu \mathrm{g} / \mathrm{mL}$ in plasma and $0.002 \mu \mathrm{g} / \mathrm{mL}$ in urine. In cell culture medium, the LOD for BZP was 0.156 $\mu \mathrm{g} / \mathrm{mL}$ and for TFMPP was $0.312 \mu \mathrm{g} / \mathrm{mL}$. The LOQ for both analytes was $0.016 \mu \mathrm{g} / \mathrm{mL}$ in plasma and $0.008 \mu \mathrm{g} / \mathrm{mL}$ in urine. In cell culture medium, the LOQ for BZP was $0.312 \mu \mathrm{g} /$ $\mathrm{mL}$ and for TFMPP was $0.625 \mu \mathrm{g} / \mathrm{mL}$. As depicted in Table 3, the coefficient of variation was equal or below $20 \%$ for both BZP and TFMPP in plasma, urine and cell culture medium.

Samples stability: The samples stability was evaluated by comparing the signal of the analytes in samples processed at day 0 with the signal of samples stored at different temperatures and processed 7 and 30 days later. A coefficient of variation of $20 \%$ was considered acceptable. The samples stability data can be depicted in Table 4 . After 7 days in plasma and urine, the two compounds are stable for the three concentrations tested at two temperatures $\left(4^{\circ} \mathrm{C}\right.$ and $\left.-20^{\circ} \mathrm{C}\right)$. After 30 days in plasma, the two compounds are stable for the three concentrations at $-20^{\circ} \mathrm{C}$, with the exception of the lowest TFMPP concentration at $4{ }^{\circ} \mathrm{C}$. Marginal increases in CV\% values were also noted for BZP $(0.016 \mu \mathrm{g} / \mathrm{mL}$ at $4 \stackrel{\circ}{\circ})$ and for TFMPP $(10 \mu \mathrm{g} / \mathrm{mL}$ at $4 \stackrel{\circ}{\circ} \mathrm{C}$ and $0.016 \mu \mathrm{g} / \mathrm{mL}$ at $-20 \stackrel{\circ}{\circ})$. In urine, both substances are stable for the three concentrations at $-20^{\circ} \mathrm{C}$ after 30 days, with only a slight increase over $20 \%$ $\mathrm{CV}$ for the lowest concentration. However, at $4 \stackrel{\circ}{ } \mathrm{C}$, the calculated CV\% is generally much higher. Thus, it is possible to conclude that the two substances are stable in plasma and urine even after 30 days of storage, especially if stored at $-20{ }^{\circ} \mathrm{C}$. In cell culture medium, the samples stability was only assessed after 7 days, and it is possible to conclude that, overall, the two compounds are stable for all concentrations at both temperatures, with the exception of the highest BZP concentration $(10 \mu \mathrm{g} / \mathrm{mL})$ when stored at $4{ }^{\circ} \mathrm{C}$.

Derivatized samples stability: The derivatized samples stability was evaluated by comparing the signal of the analytes in samples injected on day 0 with the signal of samples injected in the following 5 days. The coefficient of variation was determined and values below $20 \%$ were considered acceptable. The stability of the derivatized samples is shown in Table 5. At the lowest concentration, BZP and TFMPP are stable in plasma derivatized samples until 2 days after derivatization. For the intermediate $(0.4 \mu \mathrm{g} / \mathrm{mL})$ and the high $(10 \mu \mathrm{g} / \mathrm{mL})$ concentrations, BZP and TFMPP are stable until 4 days after derivatization. In urine derivatized samples, BZP and TFMPP are stable for all the concentrations until 2 days after derivatization. In cell culture medium, BZP and TFMPP are stable for all the concentrations, at least 5 days after derivatization. Based upon these data, it is recommended that the extracts are analyzed within a relatively short period after derivatization. 
Citation: Moreira P, da Silva DD, Cunha S, et al. (2020) Development and Validation of a GC-MS Method for the Simultaneous Quantification of Two Piperazine Designer Drugs Sold in Combination as 'Legal $X$ '. Ann Toxicol 2(1):15-25

Table 4: Stability of BZP and TFMPP in plasma, urine and cell culture medium.

\begin{tabular}{|c|c|c|c|c|c|c|c|c|}
\hline & & \multirow[t]{2}{*}{ Concentration $(\mu \mathrm{g} / \mathrm{mL})$} & \multicolumn{2}{|c|}{$\begin{array}{l}\text { Plasma sample stability } \\
\text { (CV\%) }\end{array}$} & \multicolumn{2}{|c|}{$\begin{array}{l}\text { Urine sample stability } \\
\text { (CV\%) }\end{array}$} & \multicolumn{2}{|c|}{$\begin{array}{l}\text { Cell culture medium } \\
\text { sample stability (CV\%) }\end{array}$} \\
\hline & & & BZP & TFMPP & BZP & TFMPP & BZP & TFMPP \\
\hline \multirow[t]{10}{*}{ Day 7} & \multirow[t]{5}{*}{$4{ }^{\circ} \mathrm{C}$} & 0.016 & 6 & 9 & 9 & 11 & - & - \\
\hline & & 0.4 & 16 & 7 & 12 & 16 & - & - \\
\hline & & 0.625 & - & - & - & - & 15 & 4 \\
\hline & & 2.5 & - & - & - & - & 17 & 15 \\
\hline & & 10 & 6 & 6 & 15 & 14 & 30 & 15 \\
\hline & \multirow[t]{5}{*}{$-20^{\circ} \mathrm{C}$} & 0.016 & 6 & 6 & 7 & 12 & - & - \\
\hline & & 0.4 & 9 & 4 & 9 & 15 & - & - \\
\hline & & 0.625 & - & - & - & - & 8 & 8 \\
\hline & & 2.5 & - & - & - & - & 15 & 16 \\
\hline & & 10 & 10 & 13 & 15 & 13 & 23 & 12 \\
\hline \multirow[t]{6}{*}{ Day 30} & \multirow[t]{3}{*}{$4{ }^{\circ} \mathrm{C}$} & 0.016 & 22 & 112 & 11 & 53 & - & - \\
\hline & & 0.4 & 3 & 16 & 25 & 10 & - & - \\
\hline & & 10 & 6 & 22 & 45 & 33 & - & - \\
\hline & \multirow[t]{3}{*}{$-20{ }^{\circ} \mathrm{C}$} & 0.016 & 7 & 24 & 26 & 23 & - & - \\
\hline & & 0.4 & 1 & 5 & 9 & 9 & - & - \\
\hline & & 10 & 1 & 9 & 20 & 8 & - & - \\
\hline
\end{tabular}

“-”: Not determined.

Table 5: Stability of BZP and TFMPP in derivatized plasma, urine and cell culture medium.

\begin{tabular}{|c|c|c|c|c|c|c|c|}
\hline 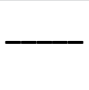 & Concentration $(\mu \mathrm{g} / \mathrm{mL})$ & $\begin{array}{l}\text { Deri } \\
\text { stab }\end{array}$ & $\begin{array}{l}\text { lasma sample } \\
\text { ) }\end{array}$ & $\begin{array}{l}\text { Deri } \\
\text { stabi }\end{array}$ & rine sample & $\begin{array}{l}\text { Deriv } \\
\text { medi }\end{array}$ & $\begin{array}{l}\text { Il culture } \\
\text { le stability (CV\%) }\end{array}$ \\
\hline & & BZP & TFMPP & BZP & TFMPP & BZP & TFMPP \\
\hline Day 1 & 0.016 & 8 & 4 & 6 & 2 & - & - \\
\hline & 0.4 & 0 & 7 & 7 & 6 & - & - \\
\hline & 0.625 & - & - & - & - & 4 & 7 \\
\hline & 2.5 & - & - & - & - & 2 & 1 \\
\hline & 10 & 2 & 3 & 7 & 7 & 2 & 1 \\
\hline Day 2 & 0.016 & 18 & 9 & 13 & 14 & - & - \\
\hline & 0.4 & 3 & 4 & 15 & 15 & - & - \\
\hline & 0.625 & - & - & - & - & 3 & 2 \\
\hline & 2.5 & - & - & - & - & 5 & 7 \\
\hline & 10 & 5 & 3 & 14 & 15 & 1 & 2 \\
\hline Day 3 & 0.016 & 61 & 54 & 93 & 72 & - & - \\
\hline & 0.4 & 12 & 2 & 28 & 26 & - & - \\
\hline & 0.625 & - & - & - & - & 0 & 1 \\
\hline & 2.5 & - & - & - & - & 3 & 9 \\
\hline & 10 & 9 & 6 & 24 & 27 & 8 & 4 \\
\hline
\end{tabular}


Citation: Moreira P, da Silva DD, Cunha S, et al. (2020) Development and Validation of a GC-MS Method for the Simultaneous Quantification of Two Piperazine Designer Drugs Sold in Combination as 'Legal $X$ '. Ann Toxicol 2(1):15-25

\begin{tabular}{|c|c|c|c|c|c|c|c|}
\hline \multirow[t]{5}{*}{ Day 4} & 0.016 & 126 & 134 & 92 & 117 & - & - \\
\hline & 0.4 & 22 & 18 & 54 & 53 & - & - \\
\hline & 0.625 & - & - & - & - & 4 & 8 \\
\hline & 2.5 & - & - & - & - & 1 & 3 \\
\hline & 10 & 11 & 8 & 52 & 72 & 0 & 3 \\
\hline \multirow[t]{5}{*}{ Day 5} & 0.016 & 139 & 139 & - & - & - & - \\
\hline & 0.4 & 43 & 39 & - & - & - & - \\
\hline & 0.625 & - & - & - & - & 12 & 15 \\
\hline & 2.5 & - & - & - & - & 1 & 9 \\
\hline & 10 & 17 & 15 & - & - & 2 & 0 \\
\hline
\end{tabular}

Table 6: Inter-day precision for BZP and TFMPP in plasma, urine and cell culture medium.

\begin{tabular}{|l|l|l|l|}
\hline & Concentration $(\mu \mathrm{g} / \mathrm{mL})$ & \multicolumn{3}{l|}{ Inter-day precision (CV\%) } \\
\cline { 2 - 4 } & & BZP & TFMPP \\
\hline Plasma & 0.016 & 6 & 11 \\
\hline & 0.4 & 9 & 11 \\
\hline Urine & 10 & 9 & 14 \\
\hline Cell culture medium & 0.016 & 11 & 8 \\
\hline & 0.4 & 12 & 8 \\
\hline & 10 & 13 & 11 \\
\hline & 0.625 & 11 & 8 \\
\hline & 2.5 & 12 & 8 \\
\hline
\end{tabular}

Table 7: Intra-day precision for BZP and TFMPP in plasma, urine and cell culture medium.

\begin{tabular}{|c|c|c|c|c|c|}
\hline & \multirow[t]{2}{*}{ Concentration $(\mu \mathrm{g} / \mathrm{mL})$} & \multicolumn{2}{|c|}{ Intra-day precision of the method (CV\%) } & \multicolumn{2}{|c|}{ Intra-day precision of the equipment (CV\%) } \\
\hline & & BZP & TFMPP & BZP & TFMPP \\
\hline \multirow[t]{3}{*}{ Plasma } & 0.016 & 5 & 6 & 2 & 0.8 \\
\hline & 0.4 & 4 & 13 & 2 & 2 \\
\hline & 10 & 9 & 15 & 0.6 & 1.3 \\
\hline \multirow[t]{3}{*}{ Urine } & 0.016 & 6 & 3 & 2 & 3 \\
\hline & 0.4 & 6 & 8 & 3 & 3 \\
\hline & 10 & 9 & 10 & 7 & 7 \\
\hline \multirow{3}{*}{$\begin{array}{l}\text { Cell culture } \\
\text { medium }\end{array}$} & 0.625 & 1 & 7 & 4 & 3 \\
\hline & 2.5 & 8 & 12 & 1 & 4 \\
\hline & 10 & 5 & 11 & 2 & 4 \\
\hline
\end{tabular}

Precision: The precision, expressed as coefficient of variation, should not exceed $15 \%$ [32]. This method showed satisfactory precision (inter-day and inter-day), since the coefficient of variation never exceeded $15 \%$. The inter-day precision was less than or equal to $14 \%$ for all concentrations of the two substances in all matrices (Table 6). In plasma, the coefficient of variation varied between $6 \%$ and $11 \%$, in urine between $8 \%$ and $14 \%$ and in cell culture medium between
$8 \%$ and $12 \%$. The intra-day precision of the method was also less than or equal to $15 \%$ for all concentrations of the two analytes in all matrices (Table 7). In plasma, the coefficient of variation ranged between $4 \%$ and $5 \%$, in urine from $3 \%$ to $10 \%$ and in cell culture medium between $1 \%$ and $12 \%$. The intraday precision of the equipment was less than or equal to $7 \%$ for all concentrations of the two substances in all matrices. In plasma, the coefficient of variation varied between $0.6 \%$ and 
Citation: Moreira P, da Silva DD, Cunha S, et al. (2020) Development and Validation of a GC-MS Method for the Simultaneous Quantification of Two Piperazine Designer Drugs Sold in Combination as 'Legal X'. Ann Toxicol 2(1):15-25

Table 8: Accuracy for BZP and TFMPP in plasma, urine and cell culture medium.

\begin{tabular}{|l|l|l|l|}
\hline & $\begin{array}{l}\text { Concentration } \\
(\mu \mathrm{g} / \mathrm{mL})\end{array}$ & \multicolumn{2}{|l|}{ Accuracy (\%) } \\
\cline { 3 - 4 } & BZP & TFMPP \\
\hline Plasma & 0.016 & 91 & 127 \\
\hline & 0.4 & 101 & 96 \\
\hline & 10 & 100 & 99 \\
\hline Urine & 0.016 & 86 & 82 \\
\hline Cell culture medium & 0.625 & 101 & 107 \\
\hline & 0.4 & 100 & 104 \\
\hline & 2.5 & 96 & 95 \\
\hline & 10 & 101 & 94 \\
\hline
\end{tabular}

$2 \%$, in urine from $2 \%$ to $7 \%$, and in cell culture medium from $1 \%$ to $4 \%$.

Accuracy: The accuracy, calculated as the percentage of target concentration, was $91-127 \%$ for plasma, $82-107 \%$ for urine and $94-101 \%$ for cell culture medium (Table 8). The accepted limit for this parameter is $100 \pm 20 \%$ [32], which was met by all test conditions, except for lowest TFMPP concentration $(0.016 \mu \mathrm{g} / \mathrm{mL})$ in plasma, for which the calculated accuracy was $127 \%$.

Extraction efficiency: The calculated recovery percentage for 4-hydroxi-3-methoxybenzylamine hydrochloride, after five independent determinations, was of $84 \% \pm 9.5 \%$ (CV\% = $11)$ in plasma, $90 \% \pm 9.7 \%(C V \%=11)$ in urine. The calculated recovery percentage for phenylpropanolamine, after three independent determinations, was of $63 \% \pm 9.6 \%(\mathrm{CV} \%=15)$ in cell culture medium. The extraction efficiency for BZP and TFMPP at the three concentrations in all matrices is described in Table 9. In plasma, the extraction efficiencies were between $79 \%$ and $96 \%$, in urine between $90 \%$ and $108 \%$, and in cell culture medium between $76 \%$ and $101 \%$. The accepted limit for this parameter is $100 \pm 20 \%$, which was always met, except for the highest BZP concentration $(10 \mu \mathrm{g} / \mathrm{mL})$ in cell culture medium, for which the extraction efficiency was $76 \%$.

Evaluation of interferences and specificity: Several blank samples of each matrix were prepared and injected to evaluate chromatographic interference. In all three matrices studied no interfering peaks at the retention times of analytes or IS were detected as can be depicted in Figure 2.

\section{Proof of applicability}

For the proof of applicability, primary rat hepatocytes were incubated with BZP and TFMPP, alone and in combination, for $24 \mathrm{~h}$. Primary hepatocytes have considerable metabolic capacity and are widely accepted as an in vitro model suitable for in vivo extrapolations. The toxicokinetic data available for both BZP and TFMPP indicate that humans and rats share the same metabolic pathways. The main metabolites produced by both species are ring-hydroxylated metabolites that can be subsequently conjugated and excreted as glucuronides
Table 9: Extraction efficiency of BZP and TFMPP in plasma, urine and cell culture medium.

\begin{tabular}{|l|l|l|l|}
\hline \multirow{2}{*}{} & \multirow{2}{*}{$\begin{array}{l}\text { Concentration } \\
(\mu \mathrm{g} / \mathrm{mL})\end{array}$} & \multicolumn{2}{|l|}{ Extraction efficiency (\%) } \\
\cline { 3 - 4 } & BZP & TFMPP \\
\hline Plasma & 0.016 & 95 & 85 \\
\hline & 0.4 & 84 & 79 \\
\hline \multirow{2}{*}{ Urine } & 10 & 96 & 89 \\
\hline \multirow{2}{*}{$\begin{array}{l}\text { Cell culture } \\
\text { medium }\end{array}$} & 0.016 & 101 & 108 \\
\hline & 0.4 & 97 & 93 \\
\cline { 2 - 4 } & 10 & 90 & 102 \\
\hline & 2.5 & 91 & 99 \\
\hline & 10 & 81 & 101 \\
\hline
\end{tabular}

and/or sulfates $[21,25,26,28,33,34]$. For both species, BZP and TFMPP are largely excreted unchanged or as glucuronide conjugates, and the quantitative analysis of the parent drugs has been used in clinical and forensic settings [21,25,33]. With our successful quantifications, the metabolic interaction between these substances in primary hepatocytes was established [35].

Under these experimental conditions, no metabolites were observed for either BZP or TFMPP. In Figure 3, representative Full Scan and SIM mode chromatograms obtained from the injection of extracellular exposure medium after incubation with BZP and TFMPP, in primary rat hepatocytes, for $24 \mathrm{~h}$ can be depicted. No interfering peaks were observed in these samples. In humans, the main metabolites of both BZP and TFMPP correspond to the ring 4-hydroxylated and 3-hydroxylated metabolites that are excreted alongside with the unchanged parent drugs, after conjugation [21,25,26,28,33]. In the case of TFMPP, for forensic and clinical purposes, the analytical data must be carefully interpreted since some of the excreted metabolites are common to other drugs such as leflunomide [26]. Therefore, the detection of the parent drug is in this case preferred. Additionally, in cases of acute intoxications high drug concentrations can be achieved in the liver and metabolic enzyme saturation often occurs, thus emphasizing the interest of the detection of the unchanged parent drugs for unequivocally proving the intake of the drug.

\section{Conclusion}

This GC-MS method was developed, optimized and validated successfully for the concurrent analysis of BZP and TFMPP. The method showed high sensitivity and an adequate performance for the simultaneous detection and quantification of these drugs in the three studied matrices (plasma, urine and cell culture medium) using only an IS in each matrix. Thus, this method proved to be an alternative to methods previously published in the literature, which are not validated or only rely on the validation for the single drugs. Linearity, detection and quantification limits, precision and accuracy of the method were all suitable for scientific, clinical and forensic use. In addition, the method proved to have quite 


\section{TIC: B5 1.Dldata.ms}

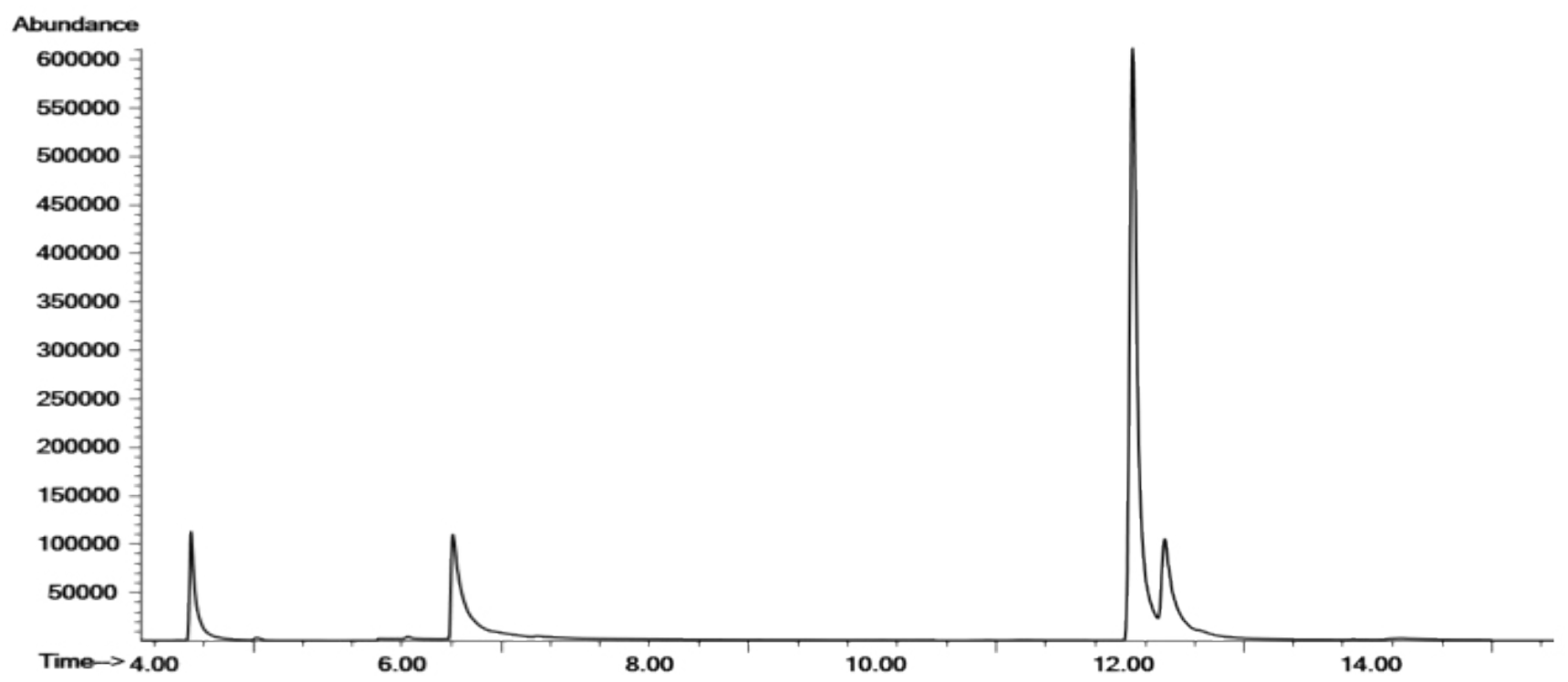

Ion 140.00 (139.70 to 140.70): B5_1.Dldata.ms Ion 272.00 (271.70 to 272.70): B5_1.Didata.ms

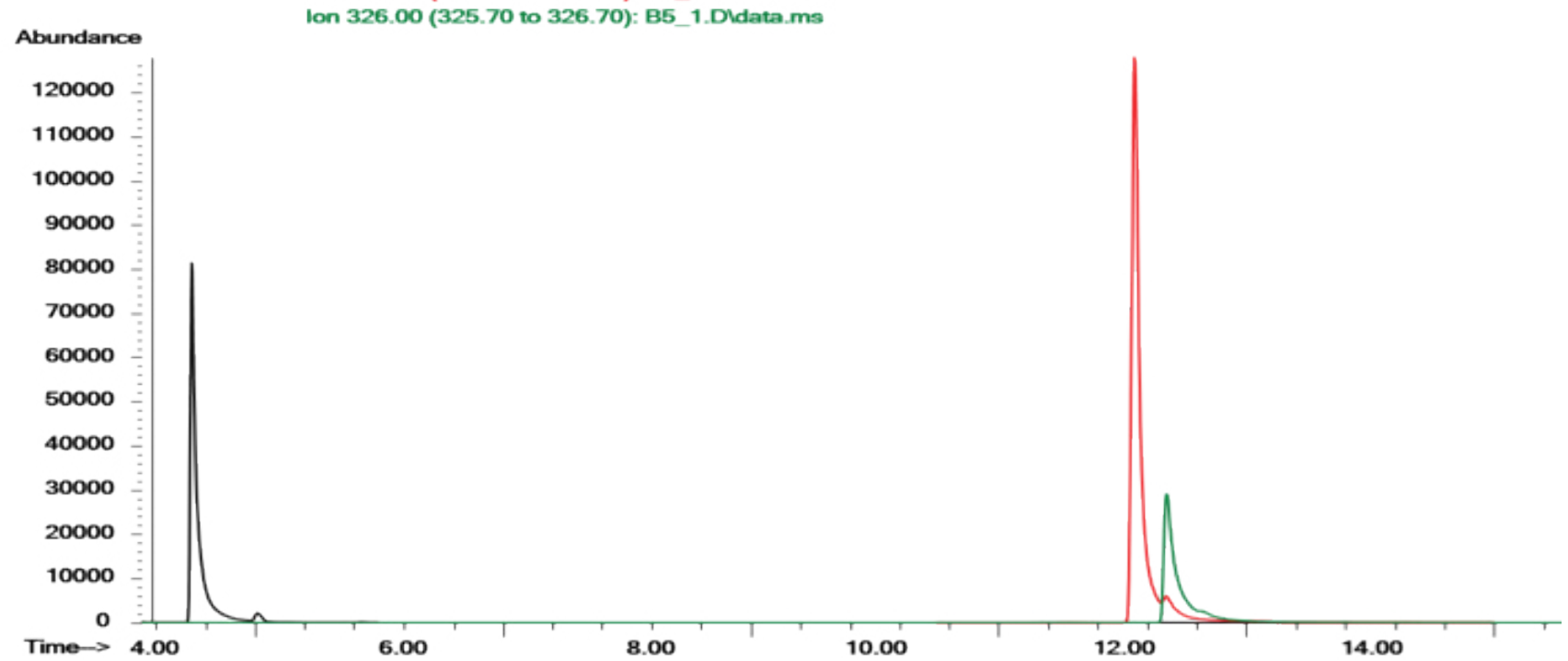

Figure 3: Full Scan and SIM mode chromatograms obtained from the injection of extracellular exposure medium after simultaneous incubation with BZP and TFMPP, in primary rat hepatocytes, for $24 \mathrm{~h}$.

acceptable extraction efficiency and absence of interferences. The selected IS proved to be suitable and easy to obtain, which avoids the use of synthesis or acquisition of multiple deuterated standards. Using a commercially available IS, the method showed a high sensitivity and linearity for a wide range of concentrations, which is particularly relevant for the clinical and forensic applications of the method. A proof of applicability of the present method was its successful use to demonstrate metabolic interactions between BZP and TFMPP involved in the in vitro hepatotoxicity of the combination of these two drugs, commercialized under the name "Legal $X$ " as a legal alternative to 3,4-methylenedioxymethamphetamine (MDMA or ecstasy). Therefore, the developed analyti- cal methodology has direct application not only for research purposes but also for the control of drug abuse in humans.

\section{Funding}

This work was financed by FEDER funds through the COMPETE 2020 - Operacional Programme for Competitiveness and Internationalisation (POCI), and by Portuguese funds through FCT - Fundação para a Ciência e a Tecnologia in the framework of the project POCI-01-0145-FEDER-029584.

\section{Conflict of Interest}

All authors declared no conflict of interest. 
Citation: Moreira P, da Silva DD, Cunha S, et al. (2020) Development and Validation of a GC-MS Method for the Simultaneous Quantification of Two Piperazine Designer Drugs Sold in Combination as 'Legal X'. Ann Toxicol 2(1):15-25

\section{References}

1. EMCDDA (2017) European drug report 2017: Trends and developments.

2. Monteiro MS, Bastos ML, Pinho PG, et al. (2013) Update on 1-benzylpiperazine (BZP) party pills. Arch Toxicol 87: 929-947.

3. Elliott S, Smith C (2008) Investigation of the first deaths in the United Kingdom involving the detection and quantitation of the piperazines BZP and 3-TFMPP. J Anal Toxicol 32: 172-177.

4. Joanne C Lin, Reem K Jan, Rob R Kydd, et al. (2011) Subjective effects in humans following administration of party pill drugs BZP and TFMPP alone and in combination. Drug Test Anal 3: 582-585.

5. Janie Sheridan, Rachael Butler, Chris Wilkins, et al. (2007) Legal piperazine-containing party pills--a new trend in substance misuse. Drug Alcohol Rev 26: 335-343.

6. Simmler LD, Rickli A, Schramm Y, et al. (2014) Pharmacological profiles of aminoindanes, piperazines, and pipradrol derivatives. Biochem Pharmacol 88: 237-244.

7. Wilkins C, Sweetsur P, Girling M (2008) Patterns of benzylpiperazine/trifluoromethylphenylpiperazine party pill use and adverse effects in a population sample in New Zealand. Drug and Alcohol Review 27: 633-639.

8. Wood DM, Button J, Lidder S, et al. (2008) Dissociative and sympathomimetic toxicity associated with recreational use of 1-(3-trifluoromethylphenyl) piperazine (TFMPP) and 1-benzylpiperzine (BZP). J Med Toxicol 4: 254-257.

9. Arbo M, Bastos M, Carmo H (2012) Piperazine compounds as drugs of abuse. Drug Alcohol Depend 122: 174-185.

10. Cohen BM, Butler R (2011) BZP-party pills: A review of research on benzylpiperazine as a recreational drug. Int J Drug Policy 22: 95-101.

11. Thompson I, Williams G, Aldington S, et al. (2006) The benzylpiperazine (BZP)/trifluoromethylphenylpiperazine (TFMPP) and alcohol safety study. Wellington.

12. Wilkins C, Girling M, Sweetsur P, et al. (2006) Legal Party Pill Use in New Zealand: Prevalence of use, availability, health harms and 'gateway effects' of Benzylpiperazine (BZP) and Trifluoromethylphenylpiperazine (TFMPP). Auckland. Centre for Social and Health Outcomes Research and Evaluation (SHORE).

13. Archer JRH, Hudson S, Jackson O, et al. (2015) Analysis of anonymized pooled urine in nine UK cities: Variation in classical recreational drug, novel psychoactive substance and anabolic steroid use. QJM 108: 929-933.

14. Baker DR, Kasprzyk-Hordern B (2011) Multi-residue analysis of drugs of abuse in wastewater and surface water by solid-phase extraction and liquid chromatography-positive electrospray ionisation tandem mass spectrometry. Journal of Chromatography A 1218: 1620-1631.

15. Chen C, Kostakis C, Irvine RJ, et al. (2013) Increases in use of novel synthetic stimulant are not directly linked to decreased use of 3, 4-methylenedioxy-N-methylamphetamine (MDMA). Forensic Sci Int 231: 278-283.

16. Gao T, Du P, Xu Z, et al. (2017) Occurrence of new psychoactive substances in wastewater of major Chinese cities. Science of the Total Environment 575: 963-969.

17. Tscharke B, Chen C, Gerber J, et al. (2016) Temporal trends in drug use in Adelaide, South Australia by wastewater analysis. Sci Total Environ 565: 384-391.

18. (2016) World drug report, United Nations Office on Drugs and Crime.
19. C Balmelli, H Kupferschmidt, K Rentsch, et al. (2001) Fatal brain edema after ingestion of ecstasy and benzylpiperazine. Dtsch Med Wochenschr 126: 809-811.

20. Chatterton C, Jones G, Singer P (2012) A case of fatal Benzylpiperazine (BZP) and Trifluoromethylphenylpiperazine (TFMPP) toxicity. Canadian Society of Forensic Science Journal 45: 150-154.

21. Antia U, Lee H, Kydd R, et al. (2009) Pharmacokinetics of 'party pill' drug $\mathrm{N}$-benzylpiperazine (BZP) in healthy human participants. Forensic Sci Int 186: 63-67.

22. Antia U, Tingle M, Russell B (2009) In vivo interactions between BZP and TFMPP (party pill drugs). N Z Med J 122: 29-38.

23. Daniel G, Guedes de Pinho P, Pontes H, et al. (2010) Gas chromatography-ion trap mass spectrometry method for the simultaneous measurement of MDMA (ecstasy) and its metabolites, MDA, HMA, and HMMA in plasma and urine. Journal of Chromatography B 878: 815-822.

24. Dias da Silva D, Carmo H, Silva E (2013) The risky cocktail: What combination effects can we expect between ecstasy and other amphetamines? Arch Toxicol 87: 111-122.

25. Antia U, Tingle MD, Russell BR (2010) Validation of an LC-MS method for the detection and quantification of BZP and TFMPP and their hydroxylated metabolites in human plasma and its application to the pharmacokinetic study of TFMPP in Humans. J Forensic Sci 55: 1311-1318.

26. Staack RF, Fritschi G, Maurer HH (2003) New designer drug 1-(3-trifluoromethylphenyl) piperazine (TFMPP): Gas chromatography/mass spectrometry and liquid chromatography/mass spectrometry studies on its phase I and II metabolism and on its toxicological detection in rat urine. Journal of Mass Spectrometry 38: 971-981.

27. Staack RF, Maurer HH (2005) Metabolism of designer drugs of abuse. Curr Drug Metab 6: 259-274.

28. Tsutsumi H, Katagi M, Miki A, et al. (2006) Metabolism and the urinary excretion profile of the recently scheduled designer drug $\mathrm{N}$-benzylpiperazine (BZP) in the rat. J Anal Toxicol 30: 38-43.

29. Cunha S (2007) Segurança e Autenticidade de Azeitonas e Azeites Varietais. Faculty of Pharmacy of the University of Porto, Porto.

30. Hajšlová J, Zrostlıkova J (2003) Matrix effects in (ultra)trace analysis of pesticide residues in food and biotic matrices. Journal of Chromatography A 1000: 181-197.

31. Maštovská K, Lehotay SJ, Anastassiades M (2005) Combination of analyte protectants to overcome matrix effects in routine GC analysis of pesticide residues in food matrixes. Anal Chem 77: 8129-8137.

32. Vorce SP, Holler JM, Levine B, et al. (2008) Detection of 1-benzylpiperazine and 1-(3-trifluoromethylphenyl)-piperazine in urine analysis specimens using GC-MS and LC-ESI-MS. J Anal Toxicol 32: 444-450.

33. Elliott S (2011) Current awareness of piperazines: Pharmacology and toxicology. Drug Test Anal 3: 430-438.

34. Staack RF, Fritschi G, Maurer HH (2002) Studies on the metabolism and toxicological detection of the new designer drug $\mathrm{N}$-benzylpiperazine in urine using gas chromatography-mass spectrometry. J Chromatogr B Analyt Technol Biomed Life Sci 773: 35-46.

35. Dias da Silva D, Silva MJ, Moreira P, et al. (2017) In vitro hepatotoxicity of 'Legal X': The combination of 1-benzylpiperazine (BZP) and 1-(m-trifluoromethylphenyl)piperazine (TFMPP) triggers oxidative stress, mitochondrial impairment and apoptosis. Arch Toxicol 91: 1413-1430. 